\title{
Sleep apnoea: what are the challenges for tomorrow?
}

Since the late 1980s and early 1990s sleeprelated breathing disorders (SRBD) have been extensively described. Many studies have been performed to understand their pathophysiological mechanisms, treatment modalities and clinical consequences. These studies have been described in many papers but also in excellent reviews and monographs, including the recently published ERS Handbook: Respiratory Medicine [1-4]. Distinction was made between sleep apnoea mainly due to upper airway collapse, obstructive apnoea (OA), and sleep apnoea caused by irregular breathing patterns, central apnoeas and Cheyne-Stokes respiration [5]. Both presentations are however also interrelated. Unstable breathing pattern, which can be seen as a starting point, can indeed lead to central apnoeas but in the case of increased upper airway collapsibility also to mixed apnoeas and obstructive apnoeas with almost no detectable central component. Today, we know that SRBD have a huge impact on society, since they can lead to many complications, including cardiovascular and metabolic ones [6-9]. Increased fatigue and daytime sleepiness are important causes of attention deficits leading to accidents at work and to car accidents [10]. Nasal CPAP (nCPAP) has been demonstrated to be highly effective in the treatment of these disorders [11]. nCPAP immediately stops the occurrence of the apnoeas (both obstructive and central) and dramatically improves symptoms and decreases cardiovascular and metabolic consequences. However, not all patients tolerate nCPAP, especially those patients with milder forms who often have a low compliance with the treatment [12]. In addition, it became also obvious that sleep apnoea has different phenotypes and that there are sex differences and important aging effects [13]. The disease has a specific presentation in children [14]. Therefore, after more than 20 years of studying pathogenetic mechanisms, clinical presentations and treatment modalities, time has come to evolve towards a personalised approach. This implies two distinct approaches: first one has to describe the disease in individual patients in detail and with many attention for the underlying pathogenetic mechanisms and genetic predisposition in order to obtain an optimal description of the genotype and phenotype; and secondly, one has to consider the treatment options that are warranted by the underlying genotype and phenotype. This approach will very much be needed in selecting patients for more selectively acting treatment modalities, such as surgical upper airway interventions, mandibular advancement devices (MAD) [15] and electrical stimulation of the upper airway dilator muscles [16]. Indeed, this approach is needed since many of these interventions are more invasive than nCPAP and often only effective in a subpopulation. While nCPAP, when tolerated, is effective in almost all patients, many of these non-CPAP therapies only work in some patients. So we need predictive diagnostics in order to be sure that costly, invasive or irreversible treatment options will work and not harm the patient. For example, this is true of MAD, used very often as an alternative for nCPAP $[15,17]$. Looking at larger series, one can see that the treatment can be very effective but only in about half of the patient. Since this treatment has some side effects and the custom-made devices have also a significant cost, prediction of the outcome is needed. This is even more so for surgical options like implanted nervus hypoglossus stimulation [16]. Several techniques have been used and are yet explored further in order to come up with some predictions. Sleep endoscopy has been used for this purpose and, although promising, no clear standards and interpretation are yet available [18]. Novel imaging techniques, using segmentation technologies and upper airway resistance calculations, are promising as well. Some preliminary studies have indicated their value in predicting the outcome of MAD; however, more studies are needed to confirm this and to see how this imaging approach can be used for the predictions of other upper airway interventions [19-21]. Making therapeutic decisions in the paediatric population with sleep apnoea, is both challenging and of crucial importance.

\section{W. De Backer}

Department of Pulmonary Medicine,

University Hospital and University of Antwerp,

Wilrijkstraat 10 B-2650 Edegem-

Antwerp Belgium

wilfried.debacker@ua.ac.be

\section{Competing interests}

W. De Backer has received research grants from GlaxoSmithKline and Astra Zeneca, and support for symposia from Boehringer, GlaxoSmithKline and Astra Zeneca. 
Additionally, for this population, genotyping and phenotyping is important. Children can develop obstructive apnoeas in relation to adenotonsillar hypertrophy (ATH) and also in relation to obesity. The obesity epidemic has also affected children and we will have to deal with differentiating OSA due to obesity from OSA due to ATH [22].

Altogether, this means that we will have to evolve from describing the disease with polysomnographic (PSG) parameters only (especially the $\mathrm{AHI}$ ) towards describing the upper airway characteristics (both anatomical and functional) using novel endoscopic and imaging technologies. Moreover, we have to rethink to position of the PSG studies. They probably are most useful in the initial differential diagnosis. But once SRBD have been detected, repeated ambulatory measurements in real-life conditions will better describe the effects of the interventions and provide more adequate information for corrective therapeutic interventions. We know that the $\mathrm{AHI}$ provided by a single PSC study is not very reliable since important variability has been described $[23,24]$. Therefore, repeated polygraphic measurements, which can be performed at lower cost, may certainly be of much more value in the treatment algorithms. Beyond describing more adequately the $\mathrm{AHI}$ by repeated polygraphic measurements, we also will have to further optimise the descriptive instruments for sleepiness and quality of life.

In summary, in the future we will need many more diagnostic tools than just PSG to describe the phenotype of the patients and to predict the outcome of novel non-CPAP interventions. This approach will especially be needed in specific population like children and the elderly. In this issue of Breathe SRBD phenotyping will be highlighted and SRBD in children and elderly will be discussed in more detail.

\section{Reference List}

1. Palange P, Simonds A. eds. ERS Handbook: Respiratory Medicine. Sheffield, ERS 2010.

2. Stradling JR, Davies RJ. Sleep. 1: Obstructive sleep apnoea/hypopnoea syndrome: definitions, epidemiology, and natural history. Thorax 2004; 59: 73-78.

3. Saboisky JP, Chamberlin NL, Malhotra A. Potential therapeutic targets in obstructive sleep apnoea. Expert Opin Ther Targets 2009; 13: 795-809.

4. Eckert DJ, Malhotra A, Jordan AS. Mechanisms of apnea. Prog Cardiovasc Dis 2009; 51: 313-323.

5. Horner RL, Bradley TD. Update in sleep and control of ventilation 2008. Am J Respir Crit Care Med 2009; 179: 528532.

6. McNicholas WT. Obstructive sleep apnea and inflammation. Prog Cardiovasc Dis 2009; 51: 392-399.

7. Riha RL, Diefenbach K, Jennum P, et al. Genetic aspects of hypertension and metabolic disease in the obstructive sleep apnoea-hypopnoea syndrome. Sleep Med Rev 2008; 12: 49-63.

8. Levy P, Pepin JL, Arnaud C, et al. Obstructive sleep apnea and atherosclerosis. Prog Cardiovasc Dis 2009; 51: 400410.

9. Levy P, Bonsignore MR, Eckel J. Sleep, sleep-disordered breathing and metabolic consequences. Eur Respir J 2009; 34: $243-260$.

10. Alonderis A, Barbe F, Bonsignore $\mathrm{M}$, et al. Medico-legal implications of sleep apnoea syndrome: driving license regulations in Europe. Sleep Med 2008; 9: 362-375.

11. Sanchez AI, Martinez P, Miro E, et al. CPAP and behavioral therapies in patients with obstructive sleep apnea: effects on daytime sleepiness, mood, and cognitive function. Sleep Med Rev 2009; 13: 223-233.

12. Yetkin 0, Kunter E, Gunen H. CPAP compliance in patients with obstructive sleep apnea syndrome. Sleep Breath 2008; $12:$ 365-367.

13. Launois SH, Pepin JL, Levy P. Sleep apnea in the elderly: a specific entity? Sleep Med Rev 2007; 11: 87-97.

14. Verhulst SL, Van Gaal L, De Backer W, et al. The prevalence, anatomical correlates and treatment of sleepdisordered breathing in obese children and adolescents. Sleep Med Rev 2008; 12: 339-346.

15. Marklund M, Stenlund H, Franklin KA. Mandibular advancement devices in 630 men and women with obstructive sleep apnea and snoring: tolerability and predictors of treatment success. Chest 2004; 125: 1270-1278.

16. Kezirian EJ, Boudewyns A, Eisele DW, et al. Electrical stimulation of the hypoglossal nerve in the treatment of obstructive sleep apnea. Sleep Med Rev 2010; 14: 299-305.

17. Marklund M. Predictors of long-term orthodontic side effects from mandibular advancement devices in patients with snoring and obstructive sleep apnea. Am J Orthod Dentofacial Orthop 2006; 129: 214-221.

18. Stuck BA, Maurer JT. Airway evaluation in obstructive sleep apnea. Sleep Med Rev 2008; 12: 411-436.

19. De Backer JW, Vos WG, Verhulst SL, et al. Novel imaging techniques using computer methods for the evaluation of the upper airway in patients with sleep-disordered breathing: a comprehensive review. Sleep Med Rev 2008; 12: 437-447.

20. Vos WG, De Backer WA, Verhulst SL. Correlation between the severity of sleep apnea and upper airway morphology in pediatric and adult patients. Curr Opin Allergy Clin Immunol 2010; 10: 26-33.

21. De Backer JW, Vanderveken OM, Vos WG, et al. Functional imaging using computational fluid dynamics to predict treatment success of mandibular advancement devices in sleep-disordered breathing. J Biomech 2007; 40: 37083714.

22. Verhulst SL, De Backer J, Van Gaal L, et al. Adenotonsillectomy as first-line treatment for sleep-disordered breathing in obese children. Am J Respir Crit Care Med 2008; 177: 1399.

23. Levendowski D, Steward D, Woodson BT, et al. The impact of obstructive sleep apnea variability measured in-lab versus in-home on sample size calculations. Int Arch Med 2009; 2: 2.

24. Levendowski DJ, Zack N, Rao S, et al. Assessment of the test-retest reliability of laboratory polysomnography. Sleep Breath 2009; 13: 163-167. 